\title{
PERENCANAAN BEBAN PENDINGIN PADA GEDUNG BARU RUMAH SAKIT PMI BOGOR DENGAN METODE CLTD
}

\author{
*Edwin Syahrial ${ }^{1}$, Rasyid Hadi Sudono ${ }^{2}$ \\ ${ }^{1,2}$ Fakultas Teknik dan Informatika, Program Studi Teknik Mesin, Universitas Dian Nusantara, Jakarta, Indonesia \\ *Email Korespondensi: \\ Edwin.syahrial@undira.ac.id
}

\section{ARTIKEL INFORMASI}

Diterima:

3 March 2021

Direvisi:

15 April 2021

Dipublikasi:

16 Mei 2021

\begin{abstract}
ABSTRAK
Sistem HVAC (Heating Ventilating and Air Conditioning) adalah sistem yang berfungsi untuk mengatur suhu dan kelembaban udara pada suatu ruangan, agar suhu dan kelembaban udara pada suatu ruangan menjadi nyaman.Dalam desain beban pendinginan gedung baru 3 lantai, menggunakan metode Cooling Load Temperature Difference (CLTD), dimana suhu dirancang pada suhu $73,4^{\circ} \mathrm{F}$ dan kelembaban 50\%. Dari hasil perhitungan perencanaan beban gedung sebesar 4954985,54 Btu / jam dan suplai udara sebesar 100690,73 CFM. Sistem pemasangan beban pendingin pada gedung menggunakan sistem VRV (Variable Refigerant Volume). Existing menggunakan 10 unit sistem VRV outdoor masing-masing di lantai 1538642,65 Btu / jam, di lantai 2 dan 3 masing-masing 505004,50 Btu / jam, untuk beban pendinginan yang optimal, dan bangunan menggunakan 215 kasat langit-langit tipe unit dalam ruangan yang telah direncanakan untuk gedung.
\end{abstract}

Keyword: HVAC, CLTD, Cooling Load, Air Supply, VRV

\section{PENDAHULUAN}

HVAC (Heating Ventilating and Air Conditioning) adalah suatu sistem yang berfungsi untuk mengatur temperatur dan kelembaban udara pada suatu ruangan sehingga kondisi temperatur dan kelembaban udara pada suatu ruangan menjadi nyaman.Sistem HVAC sangat dibutuhkan pada bangunan bangunan besar seperti perkantoran pusat perbelanjaan ataupun rumah sakit, khususnya di negara yang beriklim tropis seperti di Indonesia. Perancanaan sistem pendingin dilakukan untuk mengkondisikan suhu ruangan lebih rendah daripada temperatur lingkungan, akibat dari radiasi dan konduksi sinar matahari serta panas yang ditimbulkan oleh aktifitas manusia di dalam gedung, panas yang dihasilkan dari penggunaan peralatan elektronik, serta penerangan. Sehingga keadaan tersebut mengakibatkan terjadinya beban pendingin pada sistem HVAC.

Sehubungan akan dibangunnya gedung baru yang akan difungsikan sebagai Rumah Sakit di daerah Bogor. Tentu membutuhkan perancangan fasilitas penunjang (utilitas bangunan ) salah satunya adalah sistem HVAC. Dengan latar belakang tersebut perlu dilakukannya perancangan pada sistem HVAC dengan menggunakan data - data gedung yang akan dibangun.

Adapun identifikasi masalah pada penelitian ini adalah Akan dibangunnya gedung baru yang difungsikan sebagai rumah sakit PMI di daerah Bogor. Diperlukannya fasilitas ultilitas penujang dalam gedung seperti 
sistem HVAC yang dapat memberikan rasa nyaman bagi penghuni/pasien maupun pengunjung rumah sakit tersebut, maka untuk itu akan dilakukan perancangan sistem HVAC pada rumah sakit PMI Bogor.

Tujuan dilakukannya penelitian ini adalah Untuk mendapatkan temperature dan kelembaban yang sesuai standar kenyamanan dan kelembaban udara bagi manusia berada di kisaran 23oC dengan kelembaban udara relatif $50 \%$ melalui perancangan system pendingin ruangan. (Berdasarkan standard: Kepmenkes No.1204/ Menkes/ SK/ X/ 2004 tentang : Persyaratan Kesehatan Lingkungan Rumah Sakit Dan Standard Kualitas Ruang Rumah Sakit).

\section{KAJIAN PUSTAKA}

\section{Penyegaran Udara}

Penyegaran udara adalah suatu proses mendinginkan udara sehingga dapat mencapai temperatur dan kelembaban yang sesuai dengan yang dipersyaratkan terhadap kondisi udara dari suatu ruanga tertetu. Selain itu, mengatur aliran udara dan kebersihanya. Sistem Penyegaran udara pada umumnya dibagi menjadi dua golongan utama yaitu :

a. Penyegaran udara untuk kenyamanan

Menyegarkan udara dari ruangan untuk memberikan kenyamanan kerja bagi orang yang melakukan kegiatan tertentu

b. Penyegaran udara untu industri

Menyegarkan udara dari ruangan karena diperlukan oleh proses, bahan, peralatan, atau barang yang ada di dalamnya

\section{Sistem Refigerasi Kompresi Uap}

Pada prinsipnya, sistem refrigerasi kompresi uap sesuai dengan namanya merupakan suatu sistem yang mempergunakan kompresor sebagai alat kompresi refrigeran. Pada dasarnya sistem ini bekerja dengan memanfaatkan sifat refrigeran, dimana pada tekanan rendah, temperatur cair jenuh (saturasi) yang rendah, fasa refrigeran akan berubah menjadi uap dengan menarik kalor dari tempat yang didinginkan. Pada saat tekanan tinggi, temperatur uap jenuh (saturasi) yang tinggi, fasa refrigeran akan berubah menjadi cair dengan cara membuang kalor kelingkungan sekitar. Tentunya, untuk menciptakan sisi tekanan tinggi diperlukan suatu alat kompresi (biasa disebut kompresor) dan pada sisi tekanan rendah dipasang katup ekspansi yang akan mengakibatkan turunnya tekanan refrigeran.

Berdasarkan hal diatas, maka sistem kompresi uap ini terdiri dari beberapa langkah kerja, yaitu:

a. Proses Kompresi

Proses ini terjadi di kompresor dimana uap refrigeran dengan tekanan dan temperatur rendah yang masuk ke dalam kompresor melalui suction line (saluran hisap) dikompresi di dalam silinder kompresor sehingga temperatur dan tekanan uap refrigeran yang keluar dari kompreor melalui discharge line (saluran buang) mengalami kenaikan.

b. Proses Kondensasi

Uap superheat yang berasal dari saluran discharge (saluran keluaran kompresor) masuk menuju kondenser, dikondenser mengalami proses yang dinamakan kondensasi. Dimana kalor dari kondenser dilepaskan ke lingkungan sehingga lama-kelamaan refrigeran akan berubah fasa dari uap menjadi cair. Proses kondensasi ini terjadi pada tekanan dan temperatur yang konstan.

c. Proses Expansi

Refrigeran yang telah mengalami kondensasi di kondensor akan dialirkan menuju pipa kapiler, dimana pada pipa kapiler terjadi proses penurunan tekanan yang diikuti oleh penurunan temperatur secara isoenthalpy atau tidak terjadi perubahan enthalpy dan refrigeran sebagian berfasa cair dan sebagian berfasa gas.

d. Proses Evaporasi

Refrigeran yang telah diturunkan tekanan dan temperaturnya akan mengalami komposisi didalamnya. Pada proses ini terjadi penambahan uap pada refrigeran, sehingga fasa refrigeran adalah campuran antara cair dan uap. Dengan sedikit saja menarik kalor dari tempat yang didinginkan, maka fasanya akan berubah menjadi uap seluruhnya sampai menjadi uap jenuh. Proses inilah yang dinamakan proses evaporasi. Seperti halnya proses kondensasi, maka proses ini pun berlangsung pada tekanan dan temperatur yang konstan. 


\section{Diagram Mollier}

Adalah diagram yang digunakan untuk menganalisa keadaan termodinamis refigeran di dalam siklus refigerasi. Dimana garis tegak untuk menyataka tekanan $(\mathrm{P})$, dan garis mendatar digunakan untuk menyatakan entalpi (h). maka diagram ini disebut juga diagram p-h seperti dalam gambar 2.1

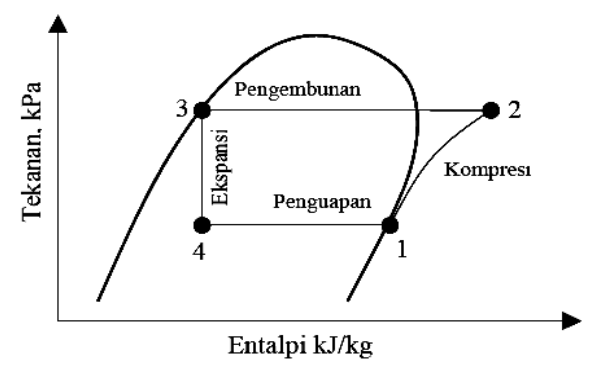

Gambar 1. Besaran Sikrkulasi Refigerasi Pada diagram Mollier (Sumber. http://www.chiller.co.id/)

\section{Perhitungan Beban Pendingin}

Perhitungan beban pendinginan merupakan cara untuk menghitung besarnya jumblah beban pendinginan suatu bangunan sebagai dasar pemilihan peralatan yang sesuai, dengan tujuan alat tersebut dapat mengatasi beban pendinginan yang ada perlu diperhatikan dalam menentukan beban pendinginan adalah sebagai berikut:

\section{a. Karakteristitk dari bangunan tersebut}

1) Material bangunan (dinding, plafon, lantai, dll)

2) Warna permukaan dari bangunan

3) Bentuk dan ukuran banguna

\section{b. Orientasi bangunan}

1) Letak gerografis

2) Pengaruh dari sinar matahari

3) Pengaruh bayangan dari bangunan lain

4) pengaruh dari pantulan panas

\section{c. Sumber panas dari dalam ruangan}

\section{Beban panas dari penghuni}

Beban panas yang berasal dari ruangan merupakan faktor yang perlu diperhitungkan pada system pengkondisian udara. Jumblah panas yang diberikan oleh penghuni yang berada dalam ruangan tergantung dari jumblah dan kegiatan atau aktifitas yang dilakukan oleh penghuni ruangan, dan panas yang diberikan itu dapat berupa panas latent dan panas sensibel.

\section{- Panas sensible}

Kalor sensibel ialah panas yang ditandai dengan perubahan temperatur.

Dimana :

$$
\mathrm{Q}_{\mathrm{s}}=\mathrm{N} \times \mathrm{SHG} \times \mathrm{CLF}
$$

$\mathrm{Q}_{\mathrm{s}}=$ Laju Perpindahan Panas Sensible (BTU/hr) N = Jumblah Orang

$\mathrm{SHG}=$ Sensible Heat Gain (BTU)

$\mathrm{CLF}=$ Cooling Load Factor

\section{- Panas latent}

Kalor latent ialah kalor yang tidak ditandai dengan perubahan temperatur

$$
\mathrm{Q}_{1}=\mathrm{N} \times \mathrm{LHG}
$$

Dimana :

$\mathrm{Q}_{1} \quad=$ Laju perindahan panas latent $(\mathrm{BTU} / \mathrm{hr})$

$\mathrm{N} \quad=$ Jumblah Orang (BTU)

$$
\mathrm{LHG}=\text { Latent Heat Gain }(\mathrm{BTU})
$$




\section{Beban panas dari penerangan}

Dimana :

$$
\mathrm{Q}_{\mathrm{s}}=3,41 \times \text { qi } \times \mathrm{F}_{\mathrm{u}} \times \mathrm{F}_{\mathrm{s}} \times \mathrm{CLF}
$$

$\mathrm{Q}_{\mathrm{s}}=$ Laju perpindahan panas Sensible (BTU/hr)

3,41 = Faktor konversi

qi = Daya lampu (Watt)

$\mathrm{F}_{\mathrm{u}} \quad=$ Faktor pemakaian lampu

$\mathrm{F}_{\mathrm{s}} \quad=$ Ballast factor

CLF $=$ Cooling Load Factor

\section{Beban Panas dari Peralatan}

$$
\mathrm{Q}_{\mathrm{s}}=(\mathrm{HG}) \times \mathrm{CLF}
$$

Dimana :

$\mathrm{Q}_{\mathrm{s}} \quad$ = Laju perpindahan panas sensible ( BTU/hr)

$\mathrm{HG}=$ Heat Gain peralatan( BTU/hr )

$\mathrm{CLF}=$ Cooling Load Factor

\section{Ventilasi}

Beban ventilasi merupakan penambahan kalor ke dalam ruangan untuk memenuhi kebutuhan oksigen bagi penghuni ruangan.

\section{- Beban sensible}

Dimana :

$$
\mathrm{Q}_{\mathrm{s}}=1,10 \times Q \times \Delta T
$$

$\mathrm{Q}_{\mathrm{s}}=$ Laju perpindahan panas sensible (BTU/hr $Q=$ Volume aliran udara ( CFM/orang)

$\Delta T=$ Beda temperatur $\left({ }^{\circ} \mathrm{F}\right)$

\section{- $\quad$ Beban Latent}

Dimana :

$$
\mathrm{Q}_{1}=4840 \times Q \times \Delta W
$$

$\mathrm{Q}_{1}=$ Laju perpindahan panas latent $(\mathrm{BTU} / \mathrm{hr})$

$Q=$ Volume aliran udara (CFM/orang)

$\Delta W=$ Beda kelembaban spesifik ( $\mathrm{lb} / \mathrm{lb})$

\section{Beban Panas Dari Luar Ruangan}

- $\quad$ Panas konduksi melalui atap, dinding, dan konduksi dinding yang berbahan kaca

Dimana :

$$
\mathrm{Q}_{\mathrm{s}}=\mathrm{U} \times \mathrm{A} \times \mathrm{CLTD}
$$

$\mathrm{Q}_{\mathrm{s}} \quad=$ Laju perpindahan panas Sebsible

(BTU/hr)
$\mathrm{A} \quad=$ Luas penampang $\left(\mathrm{ft}^{2}\right)$
CLTD $=$ Cooling Load Temperatur Difference $\left({ }^{\circ} \mathrm{F}\right)$

\section{METODE}

Metodologi penelitian merupakan tahap-tahap penelitian yang harus ditetapkan dahulu sebelum melakukan pemecahan masalah, sehingga penelitian dapat dilakukan dengan terarah dan memudahkan dalam menganalisis permasalahan yang ada. Berikut diagram alir Metode Penelitian yang digunakan dapat dilihat pada gambar 2 berikut : 


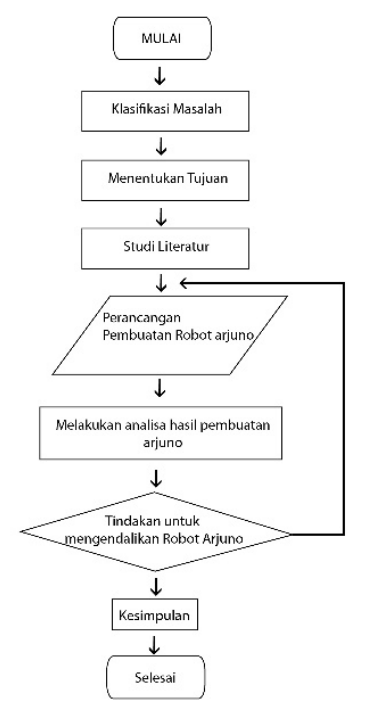

Gambar 2. Diagram alir proses penelitian

Tempat pelaksanaan penelitian dilakukan di RS PMI Bogor, pada periode waktu bulan Oktober s.d Januari 2020.

\section{Spesifikasi Data Dan Perhitungan}

Dalam perancangan HVAC dibutuhkan data-data internal gedung dan eksternal gedung, berikut data yang dapat disajikan

\section{Lokasi dan Fungsi Gedung \\ Letak geografis $\quad: 6^{\circ} \mathrm{LS}-7^{\circ} \mathrm{LS}$ dan $106^{\circ} \mathrm{BT}-108^{\circ} \mathrm{BT}$ \\ Letak Bangunan : Jl.Padjajaran Indah V No. 97 Bogor, Jawa Barat \\ Fungsi Bangunan : Bangunan difungsikan sebagai Rumah Sakit. \\ Arah Bangunan : Bangunan menghadap ke arah Selatan.}

\section{Data Fisik Gedung}

Dalam menghitung besarnya beban pendinginan yang diperlukan sebuah gedung maka perlu diketahui beberapa hal yang sangat berpengaruh dalam melakukan perhitungan tersebut .

\section{Total Beban Pendinginan Lantai 1 Sampai Dengan 3}

Dari hasil Perhitungan total QSensible Heat, QLatent Heat, Room Sensible Heat (RSH), Room Latent Heat (RLH), Room Total Heat (RTH). Lantai 1 sampai 3 dapat dilihat pada tabel 3.19.

Tabel 1. Total beban pendinginan lantai 1 sampai dengan 3

\begin{tabular}{ccccccc}
\hline \multirow{2}{*}{ No. } & \multirow{2}{*}{ Lantai } & Qs & Ql & RSH & RLH & RTH \\
\cline { 3 - 7 } & & $(\mathrm{Btu} / \mathrm{hr})$ & $(\mathrm{Btu} / \mathrm{hr})$ & $(\mathrm{Btu} / \mathrm{hr})$ & $(\mathrm{Btu} / \mathrm{hr})$ & $(\mathrm{Btu} / \mathrm{hr})$ \\
\hline 1 & Satu & 1066554.24 & 885598.29 & 1173209.66 & 974158.12 & 2147367.78 \\
\hline 2 & Dua & 687987.08 & 662464.46 & 756785.79 & 728710.91 & 1485496.69 \\
\hline 3 & Tiga & 668420.32 & 515332.48 & 735262.35 & 588858.72 & 1324121.07 \\
\hline 4 & Total & 2422961.64 & 2063395.23 & 2665257.80 & 2291727.75 & 4956985.54 \\
\hline
\end{tabular}

\section{HASIL DAN PEMBAHASAN}

\section{Hasil Analisa Perhitungan Beban Pendinginan}

Dari hasil perhitungan beban pendinginan yang dilakukan pada gedung baru Rumah Sakit PMI Bogor, dapat dihitung beban pendinginan dari lantai $1 \mathrm{~s} / \mathrm{d} 3$, dengan beban yang didapat dari hasil perencanaan perancangan. 
Setelah dilakukanya perhitungan beban pendinginan pada gedung baru Rumah Sakit PMI Bogor dengan menggunakan data-data didapat beban pendinginan sebesar 4956985.54 Btu/hr. Disajikan dengan gambar grafik dibawah ini.

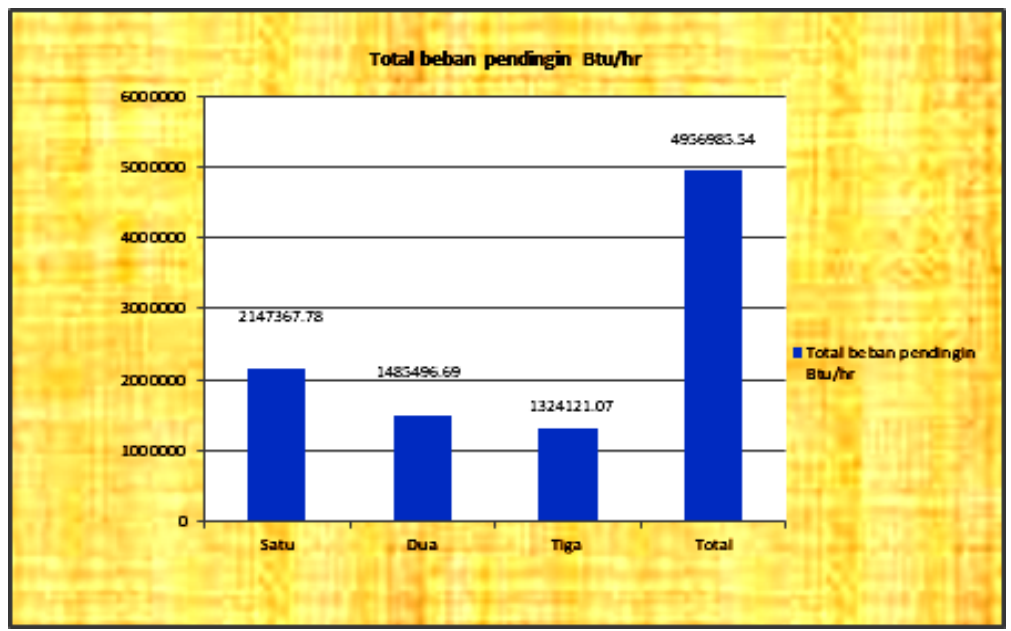

Gambar 3. Grafik Total Beban Pendingin

Dari gambar grafik, maka diperoleh, beban pendingin untuk lantai satu sebesar $2147367.78 \mathrm{Btu} / \mathrm{hr}$. Untuk beban pendingin untuk lantai dua diperoleh beban untuk pendinginan sebesar $1485496.69 \mathrm{Btu} / \mathrm{hr}$. Dan untuk lantai tiga diperoleh beban pendinganan sebesar $1324121.07 \mathrm{Btu} / \mathrm{hr}$.

\section{Hasil Analisa Perhitungan Suplai udara}

Hasil perhitungan suplai udara dapat dilihat pada gambar grafik . Dari hasil perhitungan sebelumnya di bab tiga pada sumplai udara maka didapat kebutuhan udara untuk gedung.

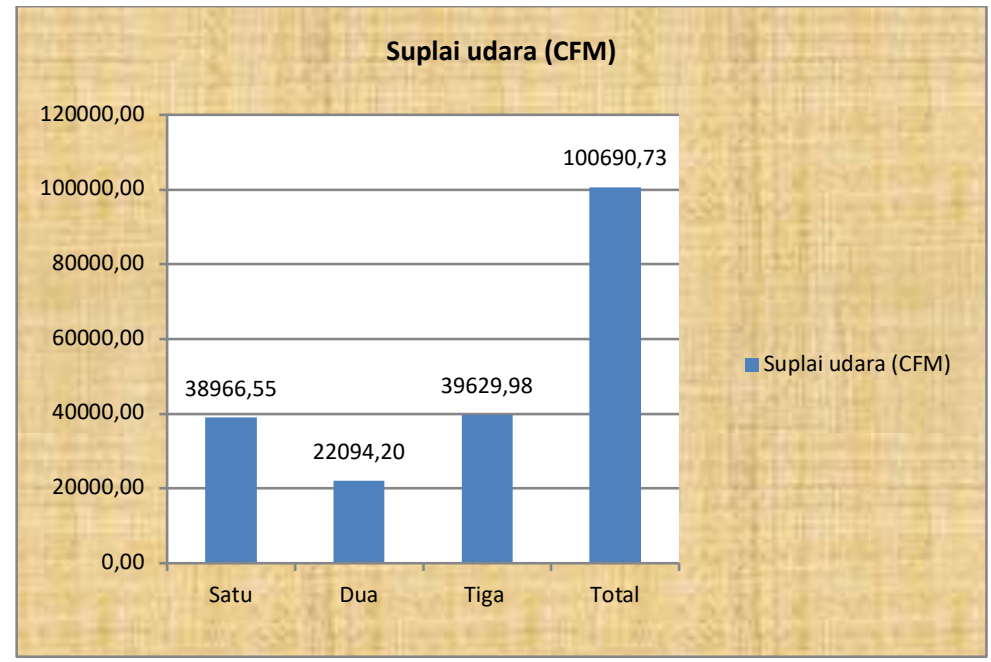

Gambar 4. Grafik Total Suplai Udara

Dari perhitungan suplai udara pada lantai satu sampai lantai tiga, memiliki hasil perhitungan total masing - masing. Untuk kebutuhan suplai udara pada lantai satu didapat hasil perhitungan sebesar 38966.55 CFM, lantai dua sebesar 22094.20 dan lantai tiga sebesar 39629.98 CFM. Total suplai udara yang dibutuhkan sebesar 100690.73CFM.

\section{KESIMPLAN DAN SARAN}


Beberapa hal yang dapat ditarik kesimpulan dari pembahasan di bab IV sebelumnya dari hasil perencanaan beban pendingin sistem VRV (Variable Refigerant Volume ), maka penulis dapat menyimpulkan beberapa hal sebagai berikut :

1) Dari perhitungan beban pendinginan latai $1 \mathrm{~s} / \mathrm{d} 3$. Diperoleh Room Total Head (RTH) pada lantai 1 sebesar 2147367,78 Btu/hr, Lantai 2 sebesar 1485496,69 Btu/hr, Lantai 3 sebesar 1324121,07 Btu/hr. Dengan total beban pendingin keseluruhan sebesar 4956985,54 Btu/hr.

2) Dari perhitungan supply udara pada lantai 1 diperoleh kapasitas udara sebesar 38966,55 CFM . Pada lantai 2 sebesar 220494,20 CFM. Pada lantai 3 sebesar 39629,98 CFM. Dengan total supply udara sebesar 100690.73 CFM.

3) Dari hasil perhitungan dapat ditentukan kapasitas Outdoor Unit system VRV:

Pada lantai 1, Ou-1.A = 537196.56 Btu/hr Ou-1.B $=534212.32 \mathrm{Btu} / \mathrm{hr} \mathrm{Ou}-1 . \mathrm{C}=538642.65 \mathrm{Btu} / \mathrm{hr}$ Ou1.D $=552941 \mathrm{Btu} / \mathrm{hr}$. Pada lantai 2, Ou-2.A $=492853.77 \mathrm{Btu} / \mathrm{hr} \mathrm{Ou}-2 . \mathrm{B}=504365.54 \mathrm{Btu} / \mathrm{hr} \mathrm{Ou}-2 . \mathrm{C}=$ 488277.38 Btu/hr .Pada lantai 3, Ou-3.A = 505004.50 Btu/hr Ou-3.B = 439181.72 Btu/hr Ou-3.C = 379934.85 Btu/hr. Jadi Bangunan dari lantai 1 s/d 3 diback up menggunakan 10 Unit Outdoor System VRV.

4) Pada Lantai 1 untuk Outdoor Ou.1.A mem-back up 18 Indoor Unit Type Ceiling Cassate, Untuk Ou.1.B mem-back up 20 Indoor Unit Type Ceiling Cassate, Untuk Ou.1.C mem-back up 27 Indoor Unit Type Cailing Cassate, Untuk Ou.1.D mem-back up 15 Indoor Unit Type Ceiling Cassate. Pada lantai 2 untuk Outdoor Ou.2.A mem-back up 30 Indoor Unit Type Ceiling Cassate, Untuk Ou.2.B mem-back up 20 Indoor Unit Type Ceiling Cassate, Untuk Ou.2.C mem-back up 17 Indoor Unit Type Cailing Cassate, Pada lantai 3, untuk Outdoor Ou.3.A mem-back up 20 Indoor Unit Type Ceiling Cassate, Untuk Ou.3.B mem-back up 30 Indoor Unit Type Ceiling Cassate, Untuk Ou.3.C mem-back up 18 Indoor Unit Type Cailing Cassate.

\section{REFERENCES}

Ashrae Handbook 2009, American Society of Heating Refrigerating and Air Conditioning Engineers Inc, Atlanta. Inch-Pound Edition

Arismunandar, Wiranto \& Heizo Saito, Penyegaran Udara, Cetakan Ke-7, Pradnya Paramita, Jakarta. 2005

Carrier Air Conditioning Company, Handbook of Air Conditioning System Design, McGraw Hill Company, New York. A Mei Ya Taiwan Edition.

Rudoy, William. 1980, Cooling and Heating Load Calculation Manual. Washington D.C : Departement of Housing and Urban Development.

Stoecker, Wilbert F \& Jerold W. Jones, Refrigerasi dan Pengkondisian Udara, Edisi Ke-2, Erlangga. Jakarta. 1994.

Syamsuri, Hasan \& Sapto Widodo, Sistem Refigerasi dan Tata Udara, Edisi Ke-1, Departemen Pendidikan Nasional, Jakarta. 2008

Mohamad Azwar Amat, Perancangan Sistem Utilitas Bangunan, Universitas Indonesia, Departemen Teknik Mesin. 